\title{
LARGE AREA CLEANING AND ACTIVATION OF FLEXIBLE ULTRA-THIN GLASS BY NON- THERMAL ATMOSPHERIC-PRESSURE PLASMA
}

\author{
${ }^{1}$ Slavomír SIHELNÍK, ${ }^{1}$ Richard KRUMPOLEC, ${ }^{1}$ Monika STUPAVSKÁ, ' Jianyu FENG, \\ ${ }^{1}$ Eva KOSOVÁ, ${ }^{1}$ Jakub KELAR, ${ }^{1,2}$ Miroslav ZEMÁNEK, ${ }^{1,2}$ Dušan KOVÁČIK, ${ }^{1}$ Mirko ČERNÁK \\ ${ }^{1}$ Masaryk University, Faculty of Science, CEPLANT, Department of Physical Electronics, Brno, \\ Czech Republic, EU, sihelnik@mail.muni.cz \\ ${ }^{2}$ ROPLASS s. r. o., Kamenice, Brno, Czech Republic, EU
}

https://doi.org/10.37904/nanocon.2020.3717

\begin{abstract}
Flexible ultra-thin glass is used as a substrate or packaging material in microelectronics engineering, where the level of cleanliness determines the quality of the final product. Surface properties of glass are governed by a surface nano-layer. Besides cleaning from coarse impurities, the demand is also for nano-decontamination, where standard cleaning proves insufficient. In microelectronics and printed flexible electronics, the bonding of thin structures deposited using printed conductive inks on glass substrates is of essential importance. The non-thermal, atmospheric-pressure plasma generated by diffuse coplanar surface barrier discharge (DCSBD) was studied as an effective pre-treatment method for cleaning and activation of glass surfaces, implementable into large-scale in-line manufacturing. Two industrial adaptations of DCSBD system were applied on two types of ultra-thin flexible glass to compare the effects of plasma treatment of glass in both relaxed, and bent state. DCSBD "Air-pillow" with a planar discharge unit is designed for contactless treatment of smooth flat largearea surfaces. A roll reactor with a concavely curved DCSBD unit is intended to exemplify its integration into roll-to-roll manufacturing. The effect of plasma treatment and its stability was analyzed with water contact angle measurement and X-ray photoelectron spectroscopy. Significant wettability improvement was achieved with both applied DCSBD geometries, with better effect uniformity and durability after using the DCSBD in the planar configuration.
\end{abstract}

Keywords: Atmospheric plasma treatment, ultra-thin flexible glass, wetting, large-area, roll-to-roll

\section{INTRODUCTION}

Naturally, the surface of glass is covered by a water nano-layer adsorbed from air humidity. This layer contains organic contaminants that hinder the quality of various deposition methods. Atmospheric pressure plasma pretreatment of glass prior to thin film deposition is studied as a unique cleaning and activation technique, which is an environmentally friendly dry alternative to the commonly used wet chemical pre-treatment [1]. Diffuse coplanar surface barrier discharge (DCSBD) operating in ambient air is a plasma source with application potential for surface treatment of various materials. An important advantage of the DCSBD is its high power density of plasma, which ensures fast, effective, and uniformly distributed activation of working gas. This predisposes the DCSBD for involvement in large-area in-line processing [2]. Development of a curved DCSBD geometry improved its applicability on flexible materials and extended its potential as an addition to roll-to-roll systems. Flexible ultra-thin glass is a future material introducing the advantageous properties of glass into the process of miniaturisation. It has found various forward-looking applications in manufacturing of printed flexible electronics like sensors, displays or photovoltaics [3]. In microelectronics and printed flexible electronics, the bonding of thin structures deposited using printed conductive inks on glass substrates is extremely important, and it can be improved by cleaning and chemical activation of the glass surface before deposition. Plasma 
exposure of glass surface could induce rearrangement of its chemical composition, which could increase its surface free energy and subsequently improve wetting for a limited time [4].

\section{EXPERIMENT}

A part of experiments to compare the contactless and contact leading of plasma source was also realized on common float glass. Soda-lime glass (SLG) samples with a thickness of 2.1 and $2.8 \mathrm{~mm}$ and a size of $20 \times 80 \mathrm{~mm}$ were manufactured in Polartherm-Flachglas $\mathrm{GmbH}$. Ultra-thin flexible glass (UFG) AF32 and D263T with a thickness of 0.03 and $0.3 \mathrm{~mm}$ and a size of $101.6 \times 101.6 \mathrm{~mm}$ were purchased from Schott AG. Tin is not involved in UFG processing, hence experiments on SLG were also carried out on the air side, which was blown over to eliminate the presence of dust. Atmospheric pressure plasma was generated in air with various DCSBD devices provided by ROPLASS, s. r. o. Sinusoidal high voltage $\sim 10 \mathrm{kV}$ is supplied to comb electrodes embedded in $\mathrm{Al} 2 \mathrm{O} 3$ ceramic for actuation of microdischarges that create a $0.3 \mathrm{~mm}$ thin plasma layer [2]. Variations of the used DCSBD implementations and their parameters are summarized in Table 1. Experiments on standard DCSBD are being realized with samples placed in holders that are guided in contact with the ceramic. DCSBD "Air-pillow" was designed for treatment of flat smooth large-area surfaces applying pneumatic levitation to perform contactless guidance [5]. "Roll" DCSBD reactor works with a concavely curved discharge unit and is intended for treatment of flexible materials that can be bent to the radius of $15 \mathrm{~cm}$ of the reactor roll [6]. Tin side detection based on UV light excitation was performed with Commercial Tin Side Detector TS1320 by CRL. The static WCA was measured with See System by Advex Instruments, s. r. o., applying $1 \mu \mathrm{l}$ drops of DI water. The XPS analysis was realized with ESCALAB $250 \mathrm{Xi}$ analytic platform by Thermo Fisher Scientific, using Al Ka source and Rowland circle monochromator. Spectra calibration, processing and fitting routines were accomplished in Avantage software.

Table 1 Setup of applied devices using DCSBD for atmospheric pressure plasma treatment

\begin{tabular}{|c|c|c|c|c|c|}
\hline Description & Geometry & $\begin{array}{c}\text { Dimensions } \\
(\mathbf{m m})\end{array}$ & $\begin{array}{c}\text { Frequency } \\
(\mathbf{k H z})\end{array}$ & $\begin{array}{c}\text { Power } \\
\mathbf{( W )}\end{array}$ & $\begin{array}{c}\text { Power density } \\
\left(\mathbf{W} / \mathbf{c m}^{3}\right)\end{array}$ \\
\hline Standard DCSBD & planar & $80 \times 195$ & 15 & 400 & 85.5 \\
\hline DCSBD "Air-pillow" & planar & $80 \times 80$ & 15 & 160 & 83.3 \\
\hline DCSBD "Air-pillow" & planar & $80 \times 195$ & 15 & 400 & 85.5 \\
\hline DCSBD "Air-pillow" & planar & $80 \times 195$ & 30 & 600 & 128.2 \\
\hline "Roll" DCSBD & curved & $80 \times 195$ & 15 & 400 & 85.5 \\
\hline
\end{tabular}

\section{RESULTS AND DISCUSSION}

Preliminary experiments were aimed at the demonstration of the importance of precise leading of DCSBD unit over the treated surface for achieving large-scale aerial uniformity of the desired effect. The comparative ageing study of contact and contactless treatment was carried out on float SLG samples, due to the fact that the fragile UFG is not suitable for contact leading. Figure 1 shows the results of WCA measured after plasma exposures with a duration of $1,3,5,7$ and $10 \mathrm{~s}$ in the chosen sequence during a week.

The reference WCA value $(26 \pm 1)^{\circ}$ was measured on the air side of previously uncleaned samples with visible pollution from dust, grease and cutting oil. In both cases, significant wettability improvement of SLG surface was achieved even after the shortest applied exposure time $1 \mathrm{~s}$; however, the lowest WCA drop was reached after the longest exposure with $10 \mathrm{~s}$ duration. In general, immediately after treatment, the values obtained in the experiments with DCSBD "Air-pillow" follow a tendency to decline about $3^{\circ}$ lower than the values from the samples modified with standard DCSBD. Furthermore, the lowest WCA of $(8.0 \pm 0.6)^{\circ}$ achieved with standard DCSBD $10 \mathrm{~s}$ treatment was a higher value than the highest WCA of $(6.4 \pm 0.3)^{\circ}$ reached with DCSBD "Airpillow" $1 \mathrm{~s}$ treatment. The smallest WCA value shown in the present ageing study on SLG is $(4.4 \pm 0.9)^{\circ}$, 
reported after DCSBD "Air-pillow" 10 s treatment. The higher uncertainty of such a low value of WCA is due to the limits of the measuring method.
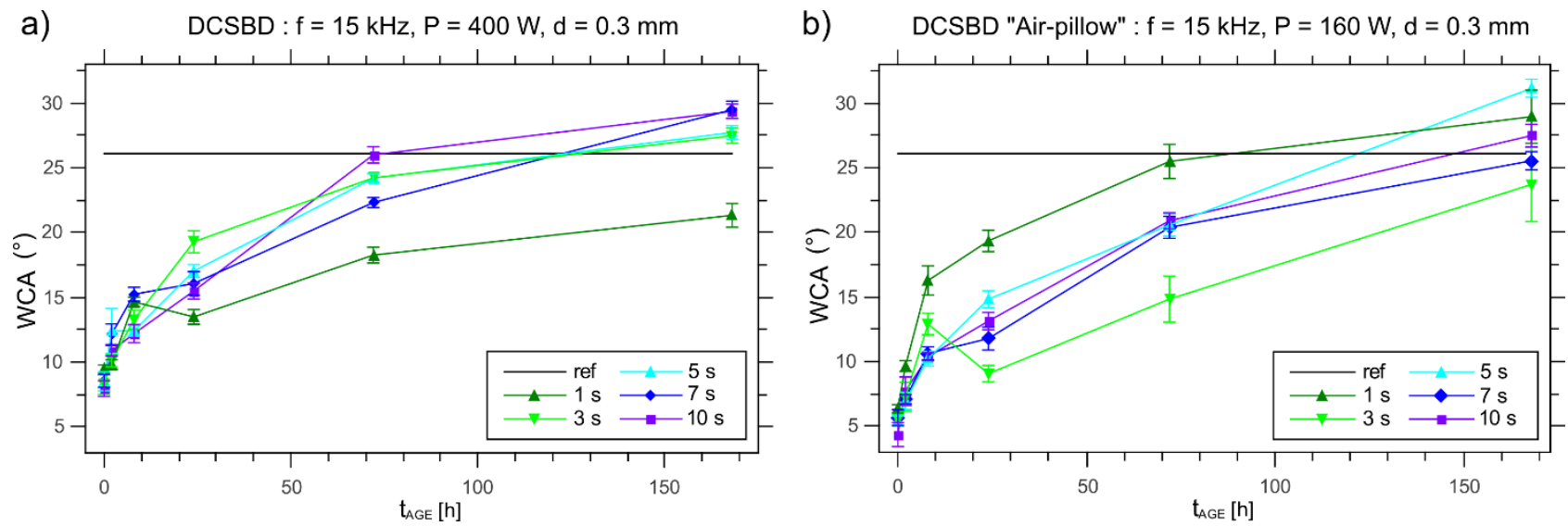

Figure 1 The ageing study of WCA on SLG treated with a) standard DCSBD and b) DCSBD "Air-pillow"

Ageing study of WCA demonstrated a gradually recovering tendency, which resulted in quite similar values for each DCSBD device for longer treatment times 5, 7 and $10 \mathrm{~s}$. WCAs recovered completely to the level of reference value on most of the samples treated with standard DCSBD after 3 days of storage and with DCSBD "Air-pillow" after 7 days. The recovery was more pronounced on the first day of storage when for $5 \mathrm{~s}$ treatment with DCSBD "Air-pillow", the WCA has grown only to $(10.2 \pm 0.6)^{\circ}$ during the first 8 hours. Demonstrable stability of hydrophilic effect with a duration of one work shift could be advantageous from the industrial point of view. The measured values and ageing trend are in a quite good accordance with the study on SLG of Homola et al. [7]; however, the results presented here vary in uncertainties that are significantly lower, particularly with the use of longer exposure times 5,7 and $10 \mathrm{~s}$. Besides better stability, DCSBD "Air-pillow" plasma treatment also showed better reproducibility, which is evident from the similarity of WCAs after longer exposures. Non-uniformity and non-reproducibility of treatment effects could be caused by insufficient removal of organic contamination with very short exposure time to DCSBD plasma [5]. Another possible source of uncertainty is unprecise guidance of treated surface, where $0.3 \mathrm{~mm}$ is the advisable distance of the surface from the ceramic of discharge system that is commonly used for DCSBD [2] in order to fully benefit from the diffuse component of its plasma generated in air at atmospheric pressure.

In order to reveal the fundamentals of wetting improvement and its ageing behaviour, the XPS analysis was accomplished on SLG samples that were exposed 1 and $3 s$ to DCSBD plasma generated on a standard device. The survey spectra registered the presence of oxygen, carbon and silicon (O1s, C1s and Si2p) in an analyzable depth profile $(\sim 3 \mathrm{~nm})$, their atomic concentrations are presented in correlation with the results of high-resolution spectra and WCA measurement in Figure 2. Atomic concentrations of $\mathrm{O}, \mathrm{C}$ and $\mathrm{Si}$ recorded on a previously uncleaned untreated sample were 40,39 and $16 \%$, respectively. Oxygen is present in bulk material which is mostly formed of silicon dioxide. Naturally, it is also included in the water film and organic contaminants originating from air humidity. Another possible source of oxygen on the plasma-treated SLG surface is chemically active functional groups incorporated into it. Applied plasma treatments induced a growth of oxygen concentration that was more significant for longer exposure time $3 \mathrm{~s}$ when it increased by $16 \%$. Ageing of 24 hours resulted in a slight decrease in oxygen content which was simultaneously followed by a more pronounced weakening of hydrophilic effect. The presence of carbon is related to the organic contamination of the surface and also to the occurrence of carbonyl and carboxyl functional groups. After the applied plasma treatments, carbon content markedly decreased, while a more significant relative decline of $27 \%$ was achieved by longer plasma exposure time $3 \mathrm{~s}$. After 24 hours of storage, carbon concentration had a tendency to grow again, which was more pronounced for the treatment of $3 \mathrm{~s}$. Silicon concentration represents the bulk material, and its change is related to the thickness of the nano-layer covering the SLG. In 
comparison with changes of concentrations of $\mathrm{O}$ and $\mathrm{C}$, the concentration of $\mathrm{Si}$ increased only slightly, when the change of $4 \%$ was reported for longer plasma exposure time $3 \mathrm{~s}$. This fact supports the expectation that both mechanisms on nano-scale are involved: cleaning effect by removal of pollution and activation by incorporation of oxygen-based groups.

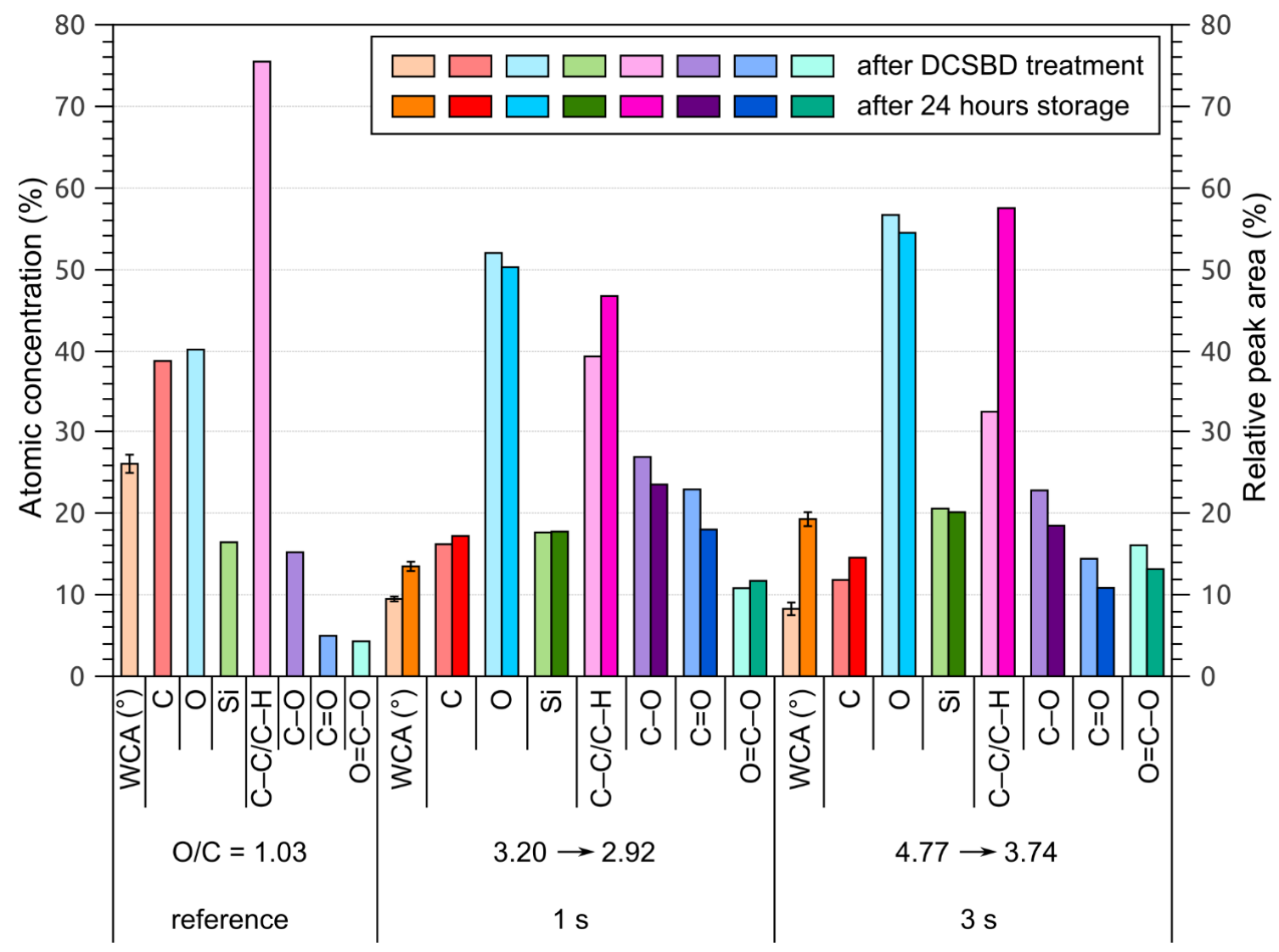

Figure 2 XPS analysis of elemental composition and carbon bonds partition compared with WCA reduction on SLG treated with standard DCSBD

High-resolution spectra aimed to differentiate between the processes during the rearrangement of surface nano-layer. The previously dominating relative peak area of $\mathrm{C}-\mathrm{C}$ and $\mathrm{C}-\mathrm{H}$ bonds, representing adsorbents of air contamination, was strongly reduced from $75 \%$ to $39 \%$ by $1 \mathrm{~s}$, and to $32 \%$ by $3 \mathrm{~s}$ plasma treatment. Breaking of $\mathrm{C}-\mathrm{C}$ and $\mathrm{C}-\mathrm{H}$ bonds is related to an oxidation process resulting in the bonding of highly reactive oxygen to the surface, which was confirmed by a significant increase of relative peak areas of $\mathrm{C}-\mathrm{O}, \mathrm{C}=\mathrm{O}$ and $\mathrm{O}-\mathrm{C}=\mathrm{O}$ bonds. The latter is a definite indicator of the formation of carboxyl functional groups that are involved in the corresponding hydrophilic improvement. The highest shown increase of the presence of bonds $\mathrm{C}-\mathrm{O}$ to $26.9 \%$ and $\mathrm{C}=\mathrm{O}$ to $23 \%$ was detected $1 \mathrm{~s}$ after DCSBD plasma treatment. After $3 \mathrm{~s}$ exposure, the relative peak area of $\mathrm{C}=\mathrm{O}$ was $14 \%$, while $\mathrm{O}=\mathrm{C}-\mathrm{O}$, increased to $16.1 \%$. The essence of this phenomenon consists in a growing quantity of active oxygen, which is generated during plasma interaction proportionally with time. After 24 hours of storage on ambient air, the concentration of $\mathrm{C}-\mathrm{C}$ and $\mathrm{C}-\mathrm{H}$ bonds increased markedly to $47 \%$ for $1 \mathrm{~s}$ and to $57 \%$ for $3 \mathrm{~s}$ treated sample. The noticed reoccurrence of $\mathrm{C}-\mathrm{C}$ and $\mathrm{C}-\mathrm{H}$ bonds is related to recovering of the activated surface with air-pollutants attracted to it, with a rate that is proportional to its oxidation. Adsorption of air humidity during storage is coincident with the decrease of relative peak areas of oxygen-containing bonds and hindering of wettability. Ageing of 24 hours after $1 \mathrm{~s}$ treatment induced a slight growth of relative peak area of $\mathrm{O}-\mathrm{C}=\mathrm{O}$ bonds, which is in contrast to the more pronounced drop recorded on the samples treated for $3 \mathrm{~s}$. This sign of more evident dissolving of $-\mathrm{COOH}$ groups together with significant growth of $\mathrm{C}-\mathrm{C}$ and $\mathrm{C}-\mathrm{H}$ bonds supports the interpretation that the impact of adsorbed air humidity is more 
pronounced on the sample with a highly oxidized surface. This phenomenon limits the applicability of plasma treatment, and as its prolonging does not provide any additional wettability improvement or better stability of the chemical composition of the SLG surface, it is advisable to use the optimal, efficient exposure time. Oxygen and carbon rearrangement induced by cleaning and chemical activation is expressed in $\mathrm{O} / \mathrm{C}$ ratio that was 1.03 on an untreated sample. Maximum rise of $\mathrm{O} / \mathrm{C}$ to 4.77 was reached with exposure of $3 \mathrm{~s}$, while DCSBD plasma treatment of $1 \mathrm{~s}$ duration showed $\mathrm{O} / \mathrm{C}$ increase to 3.20. Change of $\mathrm{O} / \mathrm{C}$ ratio after 24 hours storage was more significant for longer treatment when it dropped more than 3 times compared to $1 \mathrm{~s}$ exposure. O, C and Si proportional distribution reported in the study of Homola et al. realized with DCSBD on SLG previously pre-cleaned with 2-propanol showed generally higher values of resulting O/C ratios: initial 3.34 increased to 4.23, and 15 immediately after 1 , and $3 \mathrm{~s}$ exposure, respectively [7]. The distinction between pre-cleaning methods and proportions of carbon content supports the explanation of its origin in the organic contaminants present on the surface before plasma treatment.

Finally, the optimal DCSBD treatment time $5 \mathrm{~s}$ has been estimated for use in experiments on UFG. Results of WCA measurement on two types of flexible glass with two various geometries of DCSBD devices implementing contactless guidance are shown in Figure 3. Other investigated parameters having an influence on efficiency, uniformity and stability of surface modification were DCSBD input power and thickness of flexible glass, which were 400 and $600 \mathrm{~W}$ and 30 and 300 microns, respectively. Due to various reference WCA values on different types of flexible glass, also a relative graph of WCA reduction is included.
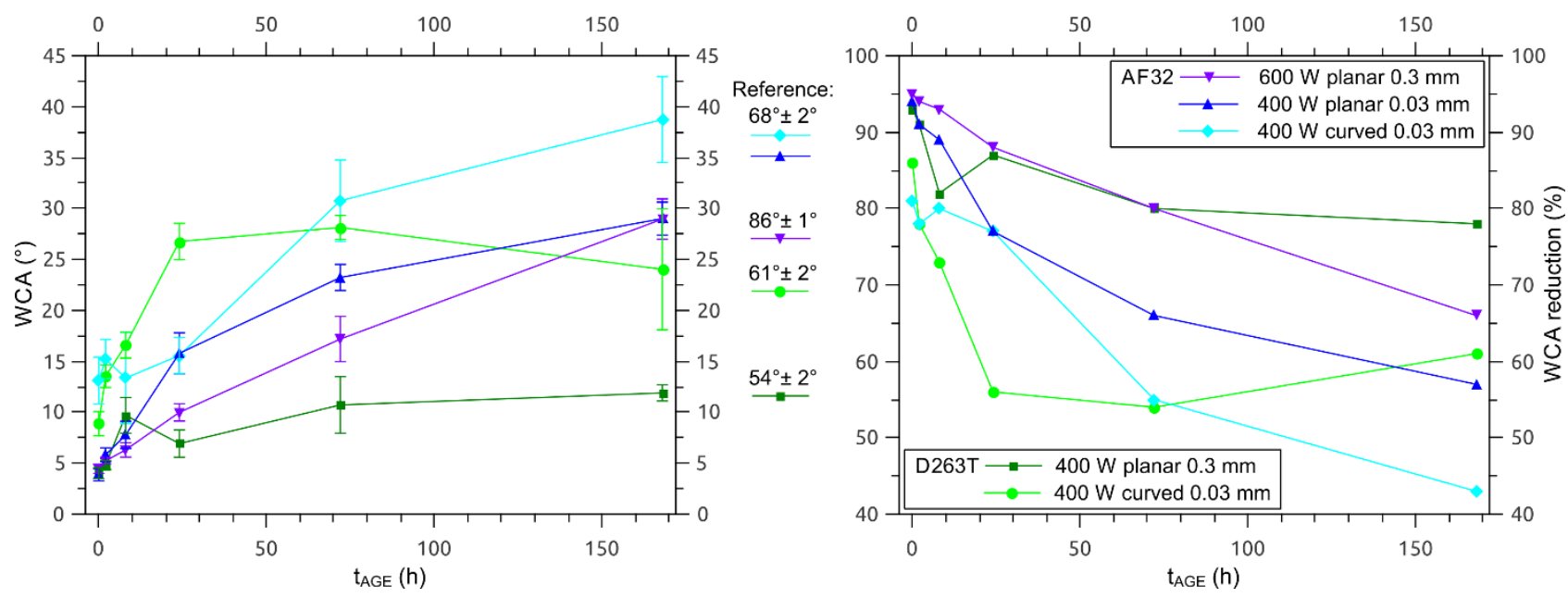

Figure 3 The ageing study of WCA of ultra-thin flexible glass treated $5 \mathrm{~s}$ with DCSBD "Air-pillow" and "roll"

The most satisfying WCA values from the view of efficiency and stability were reached with the use of DCSBD "Air-pillow", when resulting angles immediately after treatment were $(3.9 \pm 0.6)^{\circ}$ and $(4.0 \pm 0.5)^{\circ}$ on AF32 thick $30 \mu \mathrm{m}$ and D263T thick $300 \mu \mathrm{m}$. Applying higher input power of discharge $(600 \mathrm{~W})$ resulted in WCA of $(4.4 \pm 0.4)^{\circ}$, which is a value with better accuracy compared to $400 \mathrm{~W}$. Lower uncertainty caused by the increase of power supplied for generation of DCSBD plasma is related to multiplication of its microdischarges, which results in more uniform treatment. Values of WCA measured on $30 \mu \mathrm{m}$ thick flexible glass treated on "roll" DCSBD were $(8.9 \pm 1.2)^{\circ}$ on $\mathrm{AF} 32$ and $(13 \pm 2)^{\circ}$ on D263T, which are doubled and tripled compared to the measured values and uncertainties on the samples treated with DCSBD "Air-pillow". The flexibility of the ultra-thin glass allows for its bending towards the ceramic of DCSBD unit caused by attraction due to electrostatic charge coupled on the glass surface. This might be the cause of weaker uniformity of effect after DCSBD plasma treatment. Another factor affecting the uniformity of the effect is the need for a precise position of the treated surface in the active plasma volume, which is only $0.3 \mathrm{~mm}$ thin in the case of DCSBD. Contactless leading implemented in DCSBD "Air-pillow" was more suitable for treatment of samples in the form of wafers from the view of precision, which was also proven by the shown results. Ageing trends shown 
in the preliminary study on SLG were also confirmed on flexible glass. An additional investigation of increased input power demonstrated lower stability in the observed time range. A satisfying outcome in comparison to the ageing study on SLG is the fact that the measured WCAs did not recover to the level of reference value in the observed time range, neither to $60 \%$ of this value.

\section{CONCLUSION}

Plasma treatments of soda-lime glass and ultra-thin flexible glass with DCSBD plasma showed fast significant hydrophilic improvement following two mechanisms: cleaning from air-pollutants and simultaneous chemical activation by oxygen-based functional groups. Contactless guidance of planar DCSBD proved more beneficial in order to ensure the best efficiency, stability and uniformity of the treatment. The most significant WCA reduction with DCSBD "Air-pillow" on UFG reached $95 \%$ of the initial value. Nevertheless, the development in handling and packaging of UFG is aiming for an improvement of alignment important for roll-to-roll processing, which should ensure much better precision than in the presented experiments performed on waferlike samples. Applying curved DCSBD unit in a roll-to-roll system on UFG in the form of a band in a roll could potentially prevent conveying errors and thus improve the achieved effect, supposing the results could be analogous to the present results of the experiments with planar DCSBD.

\section{ACKNOWLEDGEMENTS}

This research has been supported by the projects CZ.01.1.02/0.0/0.0/16_053/0007132 funded by the European Regional Development Fund and by the German BMWi under grant No. ZF4028609AG6 and project FV40114 funded by the Ministry of Industry and Trade.

\section{REFERENCES}

[1] LISCO, F., SHAW, A., WRIGHT, A., IZA, F., WALLS, J.M. Atmospheric-pressure plasma surface activation for solution processed photovoltaic devices. Solar Energy. 2017, vol. 146, pp. 287-297.

[2] ČERNÁK, M., ČERNÁKOVÁ, L'., HUDEC, I., KOVÁČIK, D., ZAHORANOVÁ, A. Diffuse coplanar surface barrier discharge and its applications for in-line processing of low-added-value materials. EPJ Applied Physics. 2009, vol. 47, no. 2, pp. 22806 (6).

[3] CASTRO-HERMOSA, S., LUCARELLI, G., TOP, M., FAHLAND, M., FAHLTEICH, J., BROWN, T.M. Perovskite Photovoltaics on Roll-To-Roll Coated Ultra-thin Glass as Flexible High-Efficiency Indoor Power Generators. Cell Reports Physical Science. 2020, vol. 1, no. 5, pp. 100045 (17).

[4] YAMAMOTO, T., OKUBO, M., IMAI, N., MORI, Y. Improvement on hydrophilic and hydrophobic properties of glass surface treated by nonthermal plasma induced by silent corona discharge. Plasma Chemistry and Plasma Processing. 2004, vol. 24, no. 1, pp. 1-12.

[5] SIHELNÍK, S., KELAR, J., ZEMÁNEK, M., BEIER, O., KELAR TUČEKOVÁ, Z., KRUMPOLEC, M., STUPAVSKÁ, M., WITTWER, J., GRÜNLER, B., PFUCH, A. Atmospheric pressure plasma cleaning and activation of float sodalime glass prior to lamination processing. In: NANOCON 2019: 12th International Conference on Nanomaterials. Ostrava: TANGER, 2020, pp. 298-303.

[6] SHEKARGOFTAR, M., KRUMPOLEC, R., HOMOLA, T. Enhancement of electrical properties of flexible ITO/PET by atmospheric pressure roll-to-roll plasma. Materials Science in Semiconductor Processing. 2018, vol. 75, pp. 95-102.

[7] HOMOLA, T., MATOUŠEK, J., KORMUNDA, M., WU, L.Y.L., ČERNÁK, M. Plasma treatment of glass surfaces using diffuse coplanar surface barrier discharge in ambient air. Plasma Chemistry and Plasma Processing. 2013, vol. 33, no. 5, pp. 881-894. 